\title{
ENTORNO A LOS ORÍGENES DE MIGUEL DE ROMAY Y A LA ESCULTURA COMPOSTELANA EN EL TRÁNSITO DE LOS SIGLOS XVII AL XVIII (1670-1705)
}

\author{
Por \\ LEOPOLDO FERNÁNDEZ GASALLA
}

\begin{abstract}
La vida y la obra del escultor Miguel de Romay han sido objeto de atención desde antiguo, merced a su destacada actividad en el contexto del arte barroco gallego y compostelano, que ya Ceán Bermúdez resalta en su Diccionario histórico ${ }^{1}$, atención debida, en opinión de Murguía, al hecho de haber sido maestro de Felipe de Castro. Según este mismo autor, Ceán confunde a ambos, atribuyéndole a uno las obras del otro. El propio Murguía a su vez, no parece haber tenido las ideas mucho más claras, pues funde a este último con Benito Silveira en una sola persona cuando habla de don Felipe de Castro y Silveira. Tampoco llega mucho más allá en su acierto a la hora de determinar cuales fueron las piezas que salieron de su mano, interrogándose tan solo acerca de si las dos estatuas que se encuentran sobre las pilas de la iglesia de San Martín Pinario ha-
\end{abstract}

' CEÁN BERMÚDEZ, J.A.: Diccionario histórico de los más ilustres profesores de las bellas artes en España. Madrid, 1800, p. 380.

"CUADERNOS DE ESTUDIOS GALLEGOS", Tomo XLIII, Fascículo 108, Santiago 1996. 
brían sido obra suya ${ }^{2}$. Así pues, tanto Ceán como Murguía dejaron planteado un problema y, eso sí, la promesa de que quien lo clarificase arrojaría luz sobre uno de los artistas más relevantes del arte barroco gallego y español.

Diecinueve años después el canónigo López Ferreiro realiza por primera vez una atribución segura basada en fuentes documentales al identificar a Antonio Afonsín y Miguel de Romay como entalladores en 1705 del órgano del lado del Evangelio de la catedral de Santiago, y a Romay en solitario del de la Epístola en $1712^{3}$. No será sin embargo hasta 1926, cuando Pérez Costanti, comience a poner orden y a aportar la primera serie de datos fiables obtenidos tras una sistemática lectura de la documentación, publicándolos en un artículo biográfico de la Enciclopedia Espasa $^{4}$, base sobre la cual trabajaría Couselo Bouzas, ampliándola en su Galicia artística ${ }^{5}$.

En 1958, Otero Túñez, que había estudiado previamente algunas de sus realizaciones más destacadas ${ }^{6}$, aborda por fin el análisis estilístico, y no meramente cronológico como hasta entonces se había hecho, del quehacer del artista como retablista ${ }^{7}$.

Tras los sucesivos estudios publicados entorno a su figura, han permanecido en una cierta oscuridad su filiación y primeros pasos, al haberse centrado los investigadores en su etapa más fecunda, atendiendo fundamentalmente a los años posteriores a 1705 , momento en que se registraba su primer encargo conocido. La base de la presente aportación es el vaciado documental de los protocolos notariales correspondientes al distri-

${ }^{2}$ MURGUÍA, Manuel: El arte en Santiago en el siglo XVIII y noticia de los artistas que florecieron en dicha ciudad y centuria. Madrid, 1884, p. 229.

${ }^{3}$ LÓPEZ FERREIRO, Antonio: Historia de la S.A.M. Iglesia de Santiago de Compostela. Santiago. Imprenta del Seminario, 1907. Tomo IX, p. 234.

${ }^{4}$ PÉREZ COSTANTI, Pablo: «Romay, Miguel de» Enciclopedia Universal Ilustrada Europeo Americana. Madrid. Espasa-Calpe, 1926. Tomo LII, p. 187.

${ }^{5}$ COUSELO BOUZAS, José: Galicia artística en el siglo XVIII y primer tercio del XIX. Santiago. Imprenta del Seminario, 1932, p. 591.

${ }^{6}$ OTERO TÚÑEZ, Ramón: «Los retablos del crucero de la iglesia de la Compañía de Santiago de Compostela» Cuadernos de Estudios Gallegos, VIII, 26. Santiago, 1953, pp. 397-408. «El retablo mayor de San Martín Pinario». Cuadernos de Estudios Gallegos. XI, 34. Santiago, 1956, pp. 229 y ss.

${ }^{7}$ OTERO TÚÑEZ, Ramón: «Miguel de Romay, retablista» Compostellanum. Tomo III, $n^{\circ}$ 2. Santiago, 1958, pp. 192-208.

"CUADERNOS DE ESTUDIOS GALLEGOS", Tomo XLIII, Fascículo 108, Santiago 1996. 
to de Santiago conservados en los archivos gallegos ${ }^{8}$, comprendidos entre los años 1649 y 1712, lo que nos brinda una razonable seguridad acerca de que con este examen conozcamos de modo completo los datos que en estos legajos se pudiesen contener. Una vez efectuado, hemos hallado alguna información novedosa sobre las relaciones familiares y primeros pasos profesionales de Miguel de Romay.

La abundancia de artistas que con este apellido aparecen en escena en el núcleo compostelano desde el último tercio del siglo XVII hasta fines de la centuria siguiente, despertó pronto el interés de los investigadores por determinar el grado de parentesco existente entre ellos. Que sepamos, el primero en ocuparse de este asunto fue Manuel Murguía, quien supone a Miguel de Romay hermano del arquitecto Diego de Romay ${ }^{9}$. Esta conjetura es rechazada por Bonet Correa por una pura cuestión cronológica ${ }^{10}$, dado que los años transcurridos entre el fallecimiento de este último en 1694 y la fecha probable de la muerte de Miguel —entre 1737 y $1742^{11}$ lo hacen del todo imposible. Un año antes, Bouza Brey reveló la fecha y lugar de nacimiento y filiación del artista, fijándolos en 1670 en la parroquia de Dúas Eirexas ${ }^{12}$, hijo de Antonio de Romay y Alberta Rodríguez. Añadía además unas enigmáticas palabras con las que enturbiaba la claridad que acababa de aportar:

«Su nacimiento lo creemos rodeado de un cierto misterio, pero que le hace pariente del escultor Diego de Romay Junqueras, de distinguida familia».

\footnotetext{
${ }^{8}$ Archivo Histórico Universitario de Santiago, Archivo de la Catedral de Santiago, Archivo del Reino de Galicia, Archivo Histórico del Ilustre Colegio Notarial de La Coruña.

${ }^{9}$ MURGUíA. Op. cit., p. 229.

${ }^{10}$ Ibidem, p. 229. BONET CORREA, Antonio: La arquitectura en Galicia durante el siglo XVII. Madrid. CSIC, 1965, p. 432.

"COUSELO BOUZAS. Op. cit., p. 598. Este autor da como fecha de contratación de la última de sus obras 1735, recogiendo a su vez la de 1750, proporcionada por Murguía (Op. cit., p. 230), quien se basaba en que no aparecía ya mencionado en la Estadística. Sin embargo, cuando en 1742 los benedictinos de San Martín Pinario decidieron levantar los retablos del crucero de su iglesia, Romay ya había fallecido. OTERO TUÑEZ (1953). Por su parte 1737 es el año en que aparece por última vez en activo. GARCÍA IGLESIAS, José Manuel: A catedral de Santiago e o barroco. Vigo. COAG. 1990. p. 109.

${ }^{12}$ Dúas Eirexas. Forcarei (Pontevedra).
}

"CUADERNOS DE ESTUDIOS GALLEGOS", Tomo XLIII, Fascículo 108, Santiago 1996. 
Añadía además la fecha de su boda, 1692 con Inés de Valcárcel, y la paternidad del escultor Pedro de Romay Valcárcel ${ }^{13}$. Por otra parte, el conocimiento que hoy tenemos del testamento del arquitecto Diego de Romay, en el cual declara el nombre de sus hijos legítimos - María Bernarda, Micaela Ignacia, Juana y Francisco Antonio- evita cualquier especulación en cuanto a sus descendientes directos ${ }^{14}$. Pérez Costanti en su Diccionario de artistas aclara insuficientemente este particular, pues se limita a reseñar el hecho de que habiendo sido Diego de Romay vecino de la parroquia de Salomé bautizó en ella a varios de sus hijos ${ }^{15}$. Curiosamente, había sido Murguía quien, a pesar de que en su libro se ocupa de un período posterior, señaló que Diego de Romay tuvo cuatro hijas y un hijo, llamado Francisco, apadrinado por Domingo de Andrade ${ }^{16}$. En cuanto al hecho de que existiese cualquier otro tipo de vínculo familiar entre ellos, hasta el momento nada apunta en esa dirección, dado que no se le menciona en absoluto en el testamento del arquitecto o en los autos previos y posteriores a su apertura, ni en ningún otro de los testimonios escritos que sobre él y sus allegados se conservan. En uno de los documentos que aquí transcribimos, fechado pocos días después de la muerte del arquitecto, se encarga al escultor Miguel de Romay la reparación y confección de piezas para los pasos procesionales de la cofradía de la Vera Cruz, explicándose en la escritura como el difunto había sido comisionado por la misma para establecer las condiciones del contrato. Es este el único caso en que ambos aparecen relacionados, en lo que hasta el momento resulta ser, además, la primera obra documentada de Miguel de Romay, pero sin que se haga referencia a ninguna clase de parentesco entre ambos. Rodríguez Fraiz, aventura la posibilidad de que Miguel de

${ }^{13}$ BOUZA BREY, Fermín: «Los grabadores compostelanos del siglo XVIII». Compostelanum, 4, IX, 1964, pp. 240-242.

${ }^{14}$ A.H.U.S. Procotolos del distrito de Santiago, $\mathrm{n}^{\circ} 2.595$, fol. 82-137, esc. Vázquez Mosquera, Domingo. 1694-julio-12. Entorno al testamento y recuento de bienes véase nuestro artículo «Las bibliotecas de los arquitectos gallegos en el siglo XVII: Los ejemplos de Francisco Dantas Franco y Diego de Romay». Museo de Pontevedra, XLVI, 1992.

${ }^{15}$ PÉREZ COSTANTI, Pablo: Diccionario de artistas que florecieron en Galicia en los siglos XVI y XVII. Santiago. Imprenta del Seminario, 1930, p. 486.

${ }^{16}$ MURGUÍA. Op. cit., p. 229.

Ver igualmente nota 15.

"CUADERNOS DE ESTUDIOS GALLEGOS", Tomo XLIII, Fascículo 108, Santiago 1996. 
Romay fuese hijo bastardo del hermano sacerdote de Diego, Alonso de Romay Junqueras, presbítero que ejerció su ministerio en la Terra de Montes, pero sin aportar de ello prueba alguna ${ }^{17}$. Sabemos que Antonio de Castro Santos y su mujer María de Romay, hermana mayor del arquitecto, no tuvieron hijos y criaron en cambio al pequeño Francisco Antonio, que tan sólo contaba con seis años a la muerte de su padre ${ }^{18}$, por lo que queda descartada la relación a través de esta línea genealógica. No hay que desechar en cambio, la posibilidad de que fuese hijo del hermano más joven de los Romay Junqueras, Antonio, pintor de oficio. En cualquier caso no tenemos pruebas de la estancia de éste en Dúas Eirexas.

Tampoco existen pruebas definitivas de que los demás artistas de este apellido hayan sido familiares de Miguel de Romay. Couselo, considera al entallador Domingo de Romay, hermano de Miguel, y al escultor Fernando de Romay hijo del primero, dando por buenas las conjeturas de Murguía, mientras que atribuye a Miguel la paternidad de Pedro de Romay Valcárcel, igualmente escultor ${ }^{19}$.

De cualquier modo que fuese, el apellido Romay era lo suficientemente frecuente en la Galicia de los siglos XVII y XVIII, como para que se encuentre a menudo repartido por la documentación sin que nada haga pensar que cada uno de estos individuos haya de ser necesariamente deudo de los demás, por muy atractiva que resulte la idea de que todos formasen parte de una brillante dinastía de artistas.

Centrándonos ya en el examen de las nuevos documentos encontrados, digamos que la primera ocasión en la que tenemos constancia de la actividad de Miguel de Romay como escultor es la del 26 de marzo de 1693. Ese día otorga poder junto con los escultores José Vázquez de Córdoba, Jerónimo de Castro, Pedro Ramírez de Arellano, Jacobo de Eneros y Juan Antonio Rodríguez de Castiñeira, a favor del licenciado don Gregorio de Leira y Taboada, con la intención de que este obtenga una copia del pleito litigado por los pintores de la Corte, tendente a obtener su exención definitiva del pago de las alcabalas. En 1694, con veinticuatro años, contrataría la reparación de los pasos procesionales de la cofradía

\footnotetext{
${ }^{17}$ RODRÍGUEZ FRAIZ, Antonio: Canteiros e artistas de Terra de Montes e ribeiras do Lérez. Pontevedra, 1982.

${ }^{18}$ Había sido bautizado el 2 de diciembre de 1687. MURGUÍA, Op. cit., p. 229.

${ }^{19}$ COUSELO BOUZAS. Op. cit., pp. 589-599. MURGUÍA, Op. cit., p. 229.
} 
de la Vera Cruz, de los que hablaremos más adelante, mientras que tres años después, en 1697, lo encontramos junto con su esposa apadrinando a un hijo del pintor García de Bouzas ${ }^{20}$. Los treinta y cinco años con los que habría abordado una empresa de tanta categoría como la factura del primer órgano catedralicio, serían garantía de madurez más que suficiente en su oficio para clientes tan exigentes como el arzobispo fray Antonio de Monroy, su cabildo y su asesor el veterano maestro de obras catedralicio Domingo de Andrade. Sesenta y siete años tendría en el momento en que, según García Iglesias, ejecuta la última de sus obras: el «trono, arca y serafines» destinados al adorno de la sala capitular de la catedral de Santiago $(1737)^{21}$. Es posible que el momento de su muerte se produjese más cerca de esta última fecha, que de la de 1742, dada la ausencia de noticias que desde ella en adelante se produce.

Respecto a los escultores en cuya compañía se nos presenta, si bien de ninguno de ellos parece haber subsistido demasiada información, sabemos al menos lo suficiente como para que a su través prodamos relacionar a Miguel de Romay con el círculo de Mateo de Prado, al que algunos de estos pertenecían con toda seguridad. Así, Jerónimo de Castro y Losada fue su discípulo predilecto, convirtiéndose en su yerno poco antes de haber concluido su aprendizaje en $1664^{22}$. Nacido en la parroquia de Santiago de Amoroce (Celanova), su hermano, el licenciado don Benito de Castro lo asentó como aprendiz el 31 de marzo de 1658 por espacio de siete años $^{23}$. El 6 de marzo y el 1 de abril de 1666, lo hallamos firmando como testigo en sendos contratos de aprendices de su suegro, mientras que el 12 de marzo de 1668 hace lo propio en un arriendo de este a favor de un tal Jácome Agudo ${ }^{24}$. El 19 de junio de 1671 de nuevo interviene como testigo, pero esta vez en el apartamiento de un pleito por estupro entablado por el escultor Lorenzo de Neira, oficial de Mateo de Prado, contra el latonero Francisco Díaz ${ }^{25}$. Finalmente el 28 de octubre de ese año recibe

\footnotetext{
${ }^{20}$ MURGUÍA. Op. cit., p. 229.

${ }^{21}$ GARCÍA IGLESIAS. Op. cit., p. cit.

${ }^{22}$ PÉREZ COSTANTI (1930). Op. cit., pp. 100-101.

${ }^{23}$ FERNÁNDEZ GASALLA, Leopoldo: Aportación documental sobre a actividade artística compostelana entre 1649 e 1686. Santiago, 1991. Tesis de licenciatura inédita, p. 354.

${ }^{24}$ Ibidem, pp. 360-361, 365.

${ }^{25}$ Ibidem, p. 342.
}

"CUADERNOS DE ESTUDIOS GALLEGOS", Tomo XLIII, Fascículo 108, Santiago 1996. 
en arriendo de Pedro de Taboada y Camba, «maestro de arquitectura» una casa en la calle del Callobre ${ }^{26}$. Su primera obra conocida data de 1675, cuando se le encargó una imagen de San Antonio destinada a la capilla melidense del mismo nombre ${ }^{27}$. El 5 de abril de 1677 otorgaba carta de pago a favor de doña Mariña Suárez, viuda de Francisco Álvarez, en razón de una imagen de San Francisco y un relieve de las Ánimas esculpidos para la capilla que este había mandado fundar en la iglesia de Santa María de Bardaos (San Sadurniño) ${ }^{28}$. Diez y siete meses después, según conocemos por Pérez Costanti, contrató la ejecución de un relieve en forma de ramo que se sacaba en la procesión de la víspera de Nuestra Señora de la O, con el mayordomo de la cofradía del Rosario ${ }^{29}$. En 1681 se le expidió título conforme figuraba entre los 39 ministros que tenía de plantilla la catedral de Santiago ${ }^{30}$. Sabemos también que a la altura del 28 de mayo de 1685 ostentaba el cargo de mayordomo de la cofradía de San José, porque en esa fecha otorgó concordia con los capellanes de la capilla de don Lope de la catedral, para depositar en ella un arca en la que guardar la cera empleada en los actos religiosos gremiales ${ }^{31}$. Ese mismo año se ocupó del arreglo de la «cabeza y manos del Santo Cristo que está encima del altar de Nuestra Señora de la Soledad» también en el templo apostólico $^{32}$. En 1688 se hallaba en Orense, ciudad en la que sale como fiador en el contrato firmado por Pedro de Taboada, para realizar el retablo de la Transfiguración de la iglesia de Santo Domingo. En opinión de García Iglesias de este dato podría deducirse una colaboración entre ambos, que llenaría el hueco dejado por la muerte de Bernardo Cabrera $(\dagger 1663)$ y Mateo de Prado $(\dagger 1677)$. El contrato de arriendo antes mencionado confirma que su relación personal duraba desde hacía años. Tam-

\footnotetext{
${ }^{26}$ Ibidem, p. 273.

${ }^{27}$ PÉREZ COSTANTI (1930). Op. cit., p. 101.

${ }^{28}$ FERNÁNDEZ GASALLA. Op. cit., p. 333.

${ }^{29}$ PÉREZ COSTANTI (1930). Op. cit., p. 101.

${ }^{30}$ Ibidem.

${ }^{31}$ FERNÁNDEZ GASALLA. Op. cit., p. 338. La cofradía de San José fundada en los años cincuenta de este siglo, agrupaba a una parte de los artesanos de la madera (carpinteros, toneleros, entalladores y escultores), lo que no era obstáculo para miembros de estos oficios perteneciesen también a la de San Tomé, en la que convivían con los canteros.

${ }^{32}$ GARCÍA IGLESIAS. Op. cit., p. 106.
}

"CUADERNOS DE ESTUDIOS GALLEGOS", Tomo XLIII, Fascículo 108, Santiago 1996. 
bién en 1688 recibió el pago de 50 reales por las imágenes de San Benito y San Antonio, que estaba haciendo para los colaterales de Santa María do Campo (O Irixo. Orense) ${ }^{33}$.

Finalmente, parece cierta su participación en los trabajos de construcción del baldaquino del monasterio de Oseira, dado que firma como testigo en el contrato con Juan Carballo para su pintura y dorado el 17 de noviembre de $1689^{34}$.

En cuanto a José Vázquez de Córdoba, que en 1674 ejercía como oficial de Mateo de Prado ${ }^{35}$, quizás entrase a su servicio por ser familiar de su esposa, María de Córdoba, como parece indicar su segundo apellido, claramente inusual en el Santiago de entonces, lo cual explicaría por otra parte el que no se haya encontrado su contrato de aprendizaje. Su primera obra conocida es la talla de seis efigies destinadas al retablo de la capilla de las Ánimas de la antigua iglesia de San Francisco de Santiago, contratada en $1683^{36}$. En 1708 hizo las estatuas para el retablo de la Virgen de la O de la iglesia de San Paio, encargado a Jacinto de Barrios por la cofradía de los sastres ${ }^{37}$, momento en el cual perdemos su rastro.

Jacobo o Jácome de Eneros entró en el taller de Jerónimo de Castro en abril de 1674, pero al cabo de 30 meses decidió casarse, por lo cual hubo de realizar un nuevo contrato con su maestro, otorgado el 18 de octubre de 1677 comprometiéndose a asistirlo durante otro año y medio y acabar su adiestramiento ${ }^{38}$. En 1683 hizo posturas en el remate de las esculturas del citado retablo de la capilla de Ánimas. Unos años más tarde, en 1686, aparece otorgando su voto como vecino de Santiago en la elección de procurador general de la ciudad a favor de Diego de Romay ${ }^{39}$. Teniendo en cuenta que su figura no vuelve a surgir hasta el otorgamiento del poder en cuestión, es probable que su trabajo se ciñese al de un simple colaborador de Jerónimo de Castro. Otro tanto sucede con Pedro Rodríguez de Arellano y Juan Antonio Rodríguez Castiñeira. De este último ni antes ni

\footnotetext{
${ }^{33}$ HERVELLA VÁZQUEZ, José: «Mateo de Prado y su escuela en Ourense. Obras documentadas». Porta da Aira, 1, 1988.

${ }^{34}$ PÉREZ COSTANTI (1930). Op. cit., p. 88.

${ }^{35}$ Ibidem, p. 455.

${ }^{36}$ Ibid., p. 544

${ }^{37}$ COUSELO BOUZAS (1930). Op. cit., p. 645.

${ }^{38}$ FERNÁNDEZ GASALLA. Op. cit., p. 334.

${ }^{39}$ A.H.U.S. Sección Archivo Histórico Municipal de Santiago. Libro de consistorios municipales de 1686, fol. 349 y ss.
}

"CUADERNOS DE ESTUDIOS GALLEGOS", Tomo XLIII, Fascículo 108, Santiago 1996. 
después de este momento volvemos a tener noticias, mientras que a Rodríguez de Arellano lo encontramos en la citada puja del retablo de las Ánimas de 1683. Aunque pudiesen haber emprendido trabajos por cuenta propia, resulta más creíble imaginarlos como gregarios de otros artistas de mayor fuste.

Por otra parte, el precisar si fue Vázquez de Córdoba o Jerónimo de Castro el maestro de Miguel de Romay adquiere, en nuestra opinión, un lugar secundario una vez adscrito con una relativa certeza al círculo de los discípulos de Mateo de Prado. Mucho más interesante es el enlace que se tiende entre estas dos cumbres de la escultura de sus respectivos momentos: Mateo de Prado brillará de manera indiscutible en el panorama santiagués comprendido entre los años 1640 y 1677, mientras Miguel de Romay hará lo propio entre 1705 y 1735 . La influencia de los tipos iconográficos de Gregorio Fernández en las primeras esculturas de Romay, señalada por Otero Túñez, discurriría por lo tanto a través de Prado y sus discípulos, al haberse movido ése en el círculo de influencia del gran maestro de Valladolid ${ }^{40}$.

Entre medias, la ausencia de una personalidad cimera cabe atribuirla a varias causas. En primer lugar, la concepción de los retablos cambia considerablemente, pues se pasa de una estructura coordinada en la que la escultura protagoniza con rotundidad los conjuntos, ejecutaba bien en bulto redondo bien en relieve, a una organización subordinada en la cual las figuras a duras penas se hacen notar entre las gigantescas columnas salomónicas que soportan los conjuntos. La especialización en escultores y entalladores que había provocado la primera de estas tipologías, cuyo más cualificado ejemplo había sido la asociación entre Matẹ de Prado y Bernardo Cabrera en los años centrales del siglo XVII, va cediendo terreno en favor del entallador - escultor al estilo de Miguel de Romay. Acaso una cierta inadaptación de los discípulos de Prado a este nuevo modo de trabajo les causó dificultades, pero otro motivo posible es la propia casualidad de que faltase por entonces un digno sucesor de Mateo de Prado. Ya en 1666, cuando éste decide renunciar al contrato para entallar ocho ángeles destinados al baldaquino catedralicio del Apóstol, expone

${ }^{40}$ OTERO TÚÑEZ, Ramón: «Escultura». En VALDIVIESO, E; OTERO, R.; URREA, J.: Historia del Arte Hispánico. El Barroco y el Rococó. Madrid. Alhambra, 1980, pp. 208-209.

"CUADERNOS DE ESTUDIOS GALLEGOS", Tomo XLIII, Fascículo 108, Santiage 1996. 
al cabildo que tenía persona de toda satisfacción que viniese de Castilla para hacerlos ${ }^{41}$. Así pues, excluido el propio Prado, tampoco en ese momento parece que hubiese ningún escultor con la talla necesaria para afrontar tareas de envergadura y por lo tanto, ningún otro taller capaz de formar discípulos competentes.

Como quiera que fuese, desde 1677 a 1705 se produce una situación en la que ninguno de los escultores presentes por entonces en Santiago parece descollar particularmente. La inmiscusión puntual en el núcleo compostelano de artistas foráneos como Esteban de Cendón Buceta, vecino de Pontevedra (1689), José Domínguez Bugarín, procedente de Tui (1700) o incluso Francisco Castro Canseco, venido de Orense en la tardía fecha de $1714^{42}$, junto con la dispersión de los encargos entre otros de los que apenas se sabe nada ${ }^{43}$, serían síntomas evidentes de la ausencia de talleres de retablística y escultora con el vigor y capacidad de irradiación que en otro tiempo habían tenido los de Bernardo Cabrera y Mateo de Prado. En 1686, en la ya mencionada lista de votantes a favor del arquitecto Diego de Romay como procurador general del ayuntamiento de Santiago, único cargo edilicio elegido por los vecinos, localizamos a 18 individuos relacionados con el mundo de la talla y la escultura. Tan sólo hay entre ellos dos escultores: Jacobo de Eneros y Jerónimo de Castro. Reconocemos también a Jerónimo Patiño, entallador que colaboró con Antonio de Afonsín en varios retablos, - quien por cierto no aparece en la relación-, Andrés García, Juan de Cabrera, hijo de Bernardo Cabrera ${ }^{44}$

${ }^{41}$ El 8 de diciembre se firmó el contrato con Pedro del Valle, vecino de Villafranca del Bierzo. El contrato con Mateo de Prado se había firmado el 30 de junio de 1665. CARRO GARCÍA, Jesús: «Del románico al barroco: Vega Verdugo y la Capilla Mayor de la Catedral de Santiago». C.E.G. 52, XVII, 1962, pp. 234-238 y 240.

${ }^{42}$ PÉREZ COSTANTI (1930). Op. cit., p. 137. COUSELO BOUZAS. Op. cit., p. 262 y 276.

${ }^{43}$ Aparte de los ya citados y de Pedro do Campo, Andrés García, y Pedro de Meiranes Valladares, estarían el malogrado Juan de Seoane y José del Valle. PÉREZ COSTANTI (1930). Op. cit., pp. 83, 227, 379, 510 y 535.

${ }^{44}$ Andrés García ejecutaría en 1697 el retablo de San José de la capilla de San Andrés en la Catedral. Vid. nota anterior. Sobre Juan de Cabrera vid. PÉREZ COSTANTI (1930), Op. cit., p. 78, COUSELO BOUZAS, Op. cit., p. 214 y FERNÁNDEZ GASALLA, Leopoldo: «La autoría del retablo de Montederramo: Bernardo Cabrera y su hijo Juan de Cabrera, retablistas del escultor Mateo de Prado» Brigantium, 6, 19891990.

"CUADERNOS DE ESTUDIOS GALLEGOS", Tomo XLIII, Fascículo 108, Santiago 1996. 
y Jacinto de Barrios, a quien ya nos hemos referido ${ }^{45}$. Los demás nombres nos resultan desconocidos. Aunque el voto no era obligatorio y algunos de los artistas pudieron estar por entonces ausentes de la ciudad, el masivo interés con que los artesanos de oficios artísticos y constructivos auparon a su representante al citado oficio concejil nos proporciona una razonable certeza de que la mencionada lista se aproxima a lo que podría haber sido un censo de los miembros de la profesión.

Por todo esto, asumiendo el razonamiento de Otero Túñez, quien basándose en el análisis formal de las cajas de los órganos de la catedral, concluye que el adiestramiento de Miguel de Romay como retablista debió de producirse al lado de Domingo de Andrade ${ }^{46}$, así como lo dicho sobre su aprendizaje como escultor, encontraríamos a la altura de 1705 a un artista perfectamente capacitado para emprender la brillante carrera que le llevaría a convertirse en la figura central de la escultura y la talla del Santiago del primer tercio del siglo XVIII.

En cualquier caso, todas estas cuestiones previas que nos hemos planteado, aunque tal vez de mayor transcendencia que las que nos quedan por abordar, no dejan de ser laterales a los propios documentos transcritos. En el primero de ellos, como anticipábamos, nos encontramos con el asunto de la pretensión de los escultores de Santiago de exención del pago de las alcabalas. Fue esta una materia que provocó una larga y apasionada polémica en la España del siglo XVII ${ }^{47}$. Como es sabido, el impuesto de la alcabala suponía el pago de un $10 \%$ sobre el valor de toda compraventa, por lo cual eran los intercambios de bienes y no los servicios los que resultaban afectados. En esto se basaron los pintores madrileños cuando tomaron como partida de su argumentación para evadir su pago, el hecho de que los plateros cotizasen por el metal que vendían y no por el trabajo incorporado de cada pieza. En su caso estaba claro que no era por los colores y su soporte por lo que el cliente pagaba, sino por la realización. La costumbre era otro punto fuerte de su defensa, dado que ellos nunca habían satisfecho tal impuesto. Esta controversia generó una abundante literatura, así como numerosos pleitos en los que se vieron implicados

\footnotetext{
${ }^{45}$ Vid. nota 32.

${ }^{46}$ OTERO TÚÑEZ (1958). Op. cit., p. 197.

${ }^{47}$ LAFUENTE FERRARI, Enrique: «Borrascas de la pintura y triunfos de su excelencia». Archivo Español de Arte, 1944, p. 77.
}

"CUADERNOS DE ESTUDIOS GALLEGOS", Tomo XLIII, Fascículo 108, Santiago 1996. 
destacados artistas de la Corte durante todo el siglo XVII ${ }^{48}$. Dado que las actitudes de los alcabaleros eran semejantes en Madrid y en Santiago, siendo su fin último recaudar la mayor cantidad de dinero posible, no sorprende que ideas de tanta utilidad para defender las bolsas se propagasen llegando enseguida hasta Composela, como había ocurrido ya con muchas otras ciudades de la Corona. De hecho, en el recuento de los libros de Francisco Dantas Franco, maestro de obras de la catedral de Santiago, efectuado tras su muerte en $1664^{49}$, figuran los Discursos del abogado don Juan de Butrón, en los que recoge la argumentación jurídica que había empleado en el pleito de los pintores Madrileños con la Real Hacienda ${ }^{50}$. Claro está que la Galicia del siglo XVII no era tierra precisamente de pintores, pero eso no impidió a los cofradas de San Tomé de Santiago emplearlas con la misma intención. Así, el 20 de enero de 1660 encontramos a los canteros, pedreros, carpinteros y toneleros de la ciudad dando poder a procuradores para que plantasen cara a los recaudadores del impuesto de los que afirman

«[...] que dellos pretendian cobrar dichas alcabalas y cientos por razon de las piedras y maderas que labran y edifican, siendo anssi que no tienen salida dichas piedras, ni madera, ni se venden, si no es que las fabriquen a fuerza de sudor y trabaxo de sus manos y que, de su sudor $\mathrm{y}$ trabajo, no deven pagar dichas alcabalas y cientos [...], porque jamas se habia pagado cossa alguna de dichos oficios de pedreros, canteros $[\mathrm{y}]$ toneleros $[\ldots] \gg^{51}$.

A fuerza de evidente, no es necesario insistir en como los argumentos de la falta de costumbre y del valor añadido por el trabajo a los materiales empleados en la obra usados por los pintores madrileños, se repiten aquí de manera idéntica, aunque cobrando más fuerza si cabe, pues en el caso

${ }^{48}$ GALLEGO, Julián: El pintor de artesano a artista. Granada. Universidad de Granada, 1976, p. 262.

${ }^{49}$ BUTRÓN, Juan de: Discursos apologeticos en que se defiende la ingenuidad del arte de la pintura. Madrid. Luis Sánchez, 1626. Sobre la biblioteca de Francisco Dantas véase el artículo citado.

${ }^{50}$ CALVO SERRALLER, Francisco: Teoría de la pintura española del siglo de Oro. Madrid, 1981, pp. 195-201.

${ }^{51}$ FERNÁNDEZ GASALLA. Op. cit., pp. 33-34 y 106.

"CUADERNOS DE ESTUDIOS GALLEGOS", Tomo XLIII, Fascículo 108, Santiago 1996. 
de este gremio compostelano es obvio que no daba la posibilidad de la venta de piezas de arte realizadas sin contrato previo, es decir, de cuadros pintados para ser vendidos en una tienda-taller a quien pudieren interesar.

La presión fiscal de un Estado, que había contraído unas obligaciones políticas internacionales infinitamente superiores a las que su capacidad financiera le hubiese permitido atender razonablemente, no cesó durante todo el reinado de la casa de Austria. El arriendo de la recaudación a particulares, acentuó la rapacidad de los agentes de la Hacienda Pública, pues el margen entre el tanto que pagaban al Estado y lo que de los contribuyentes se obtuviese constituía su ganancia. Por ello no es de extrañar el que casi veinte años después del ejemplo que acabamos de ver, el 13 de enero de 1681, los azabacheros protestaban de nuevo contra los alcabaleros, aunque sin pretensiones de eludir por completo el tributo.

«[...] en como en virtud de despacho del señor don Gonsalo de Savedra, juez conservador de dichas alcabalas, ganado a nuestro pedimiento para que no nos perturben el que abramos nuestras tiendas y vendamos nuestras mercancias y que no cobren de nosotros alcabalas y çientos, mas que tan solamente de aquello que se estila pagar. Y mediante nos tienen registrado todas nuestras mercancias y se les ha hecho ayer, dose deste presente mes, notorio dicho despacho y en su cumplimiento de lugar, protestamos una, dos, tres y las mas veces que a nuestro derecho convenga, abrir nuestras tiendas y vender lo que agora tenemos registrado y el pagarles de y aquello que legitimamente les debieremos por raçon de dichas alcabalas y çientos $[\ldots] \rrbracket^{52}$.

El poder de los escultores, no deja de ser por lo tanto uno más en esta misma dirección. El que se reconozca la categoría de liberal para su arte interesa en tanto en cuanto comporta «preminencias, exenciones y prerrogativas concedidas por los reyes que les liberan de todo género de contribución y oficios concejiles y otras más cosas a que no deben ser obligados.», aunque no necesariamente quiera esto decir que fuesen insensibles a lo que en ello pudiese tocar al punto de honor. De hecho, ambas cosas estaban íntimamente ligadas en la mentalidad de la época.

${ }^{52}$ FERNÁNDEZ GASALLA. Op. cit., p. 34 y 451.

"CUADERNOS DE ESTUDIOS GALLEGOS", Tomo XLIII, Fascículo 108, Santiago 1996. 
No se entendía la hidalguía o la pertenencia a un estamento elevado sobre el vulgo sin la exención de impuestos.

De muy diferente carácter es el contrato de restauración de los pasos procesionales de la cofradía de la Vera Cruz. Además de por ser esta la primera obra documentada de Miguel de Romay, el documento reviste interés especial al constituirse en el primer contrato encontrado hasta ahora para la confección de los pasos procesionales de la ciudad de Santiago y creemos que aún de toda Galicia. Afirma López Ferreiro que en 1663 los gremios compostelanos llegaron a un concierto con la dicha cofradía, según el cual cada uno de ellos debía llevar su paso o misterio para dar mayor lustre a la procesión del Jueves Santo ${ }^{53}$. Sin embargo, Pérez Costanti indica que extinta esta cofradía muchos años antes se impuso a los gremios la obligación de costear la función procesional en ese año, mientras que en 1672, se convirtió en carga vecinal, siendo dos vecinos con oficio de mayordomos los que la debían costear sin posibilidad de excepciones $^{54}$. El año 1662 es ciertamente una fecha muy tardía, lo que obliga a pensar que desde mucho antes debieron de existir en nuestro territorio estos conjuntos escultóricos tan característicos de la devoción religiosa hispana. Según ha estudiado Martín González, para el núcleo vallisoletano, el primer paso procesional compuesto de varias figuras y realizado en madera y no ya en papelón, salió del taller del escultor Francisco de Rincón en 1604. Se trata del paso de la Exaltación de la Cruz, conservado hoy en el Museo Nacional de Escultura de Valladolid ${ }^{55}$. Desde esta fecha hasta la del contrato que nos ocupa median nada más y nada menos que cincuenta y nueve años, que hoy por hoy, podemos llenar con poco más que conjeturas. Los pasos procesionales estuvieron desde sus orígenes ligados a la devoción popular y por tanto a una de sus cristalizaciones más dinámicas: las cofradías. Poco se ha escrito sobre su papel como comitentes de escultura religiosa, predominando las referencias aisladas,

${ }^{53}$ LÓPEZ FERREIRO, Antonio: Fueros municipales de Santiago y de su tierra. Madrid. Ed. Castilla. 1975. (ed. facsímil de la de 1895), p. 655.

${ }^{54}$ PÉREZ COSTANTI: «La procesión de jueves Santo». Notas viejas galicianas. Xunta de Galicia, 1993, pp. 493-496.

${ }^{55}$ MARTÍN GONZÁLEZ, Juan José: «La escultura del siglo XVII en las demás escuelas españolas». En J. HERNÁNDEZ DÍAZ, J.J. MARTÍN GONZÁLEZ y J.M. PITA ANDRADE: Summa Artis. Vol. XXVI. La escultura y la arquitectura españolas del siglo XVII. Madrid. Espasa-Calpe, 1985, pp. 247-248.

"CUADERNOS DE ESTUDIOS GALLEGOS", Tomo XLIII, Fascículo 108, Santiago 1996. 
sin que se haya expuesto hasta el momento una visión de conjunto. En cualquier caso, el sentido común nos inclina a creer que la idea del paso, tal y como lo vemos ya en el Valladolid de principios del siglo XVII, no debió de tardar demasiado en asimilarse en Santiago, dado que las procesiones de Semana Santa tenían un fuerte arraigo en la ciudad desde mucho tiempo antes ${ }^{56}$. Según el Padre Pardo Villar, en 1631 la Cofradía del Rosario, sita en el convento de Santo Domingo, mandó labrar la imagen del Divino Redentor para la procesión del Santo Entierro ${ }^{57}$. Ello no confirma el que se portasen grupos escultóricos, pero si la existencia de figuras hechas ex profeso para dichas celebraciones, lo que nos encaminaría en la dirección indicada. Por otra parte, el que se encargase a Miguel de Romay la reparación y reposición de armazones, pies, manos y aún la fábrica de las cabezas de algunos personajes indica que forzosamente los pasos de la Cofradía de la Vera Cruz debían de datar de bastantes años antes. Con todo, la absoluta ausencia de referencias a obras de este tipo en el Diccionario de Pérez Costanti, no puede menos que producirnos una cierta perplejidad. Asombra que a ninguno de los miembros de la legión de entalladores y escultores que en él se registra se le encargase la confección de pasos procesionales.

En cuanto a la tarea encomendada a Romay en este caso concreto, digamos que había de trabajar sobre seis pasos propiedad de la Cofradía de la Vera Cruz: Última Cena, Oración en el Huerto, Prendimiento, Paso de la Columna o Flagelación, Ecce Homo y Paso de la Cruz a cuestas. Por el tenor del contrato, sabemos que estaban compuestos todos ellos por santos de vestir, o sea, por los consabidos soportes de cabezas y manos, cubiertos con sus correspondientes túnicas y mantos. En el primero de ellos, integrado por las trece figuras, además de construir de nuevo los armazones, como se dice que se haga con todos los de los demás pasos, había de reparar las cabezas y manos de cada una de ellas, escuipiendo una cabeza nueva para el San Juan. No queda del todo claro a causa de la deficiente redacción, si la cabeza de Cristo había de hacerse también,

${ }^{56}$ PÉREZ COSTANTI (1993). Op. cit., recoge la existencia de la procesión de jueves santo en 1570 , pero sin duda era bastante anterior.

${ }^{57}$ PARDO VILLAR, Aureliano: «La iglesia de Santo Domingo de Santiago. Cofradías en ella establecidas y sus cultos». Cuadernos de Estudios Gallegos. Santiago, 194445 , p. 650 .

"CUADERNOS DE ESTUDIOS GALLEGOS", Tomo XLIII, Fascículo 108, Santiago 1996. 
pero parece plausible pensar que si, puesto que en caso contrario no se mencionaría expresamente. En la Oración en el Huerto, el trabajo era semejante, incluida una nueva cabeza para San Juan, lo que parece lógico considerando que la de la Santa Cena se había sustituido. Para el paso del Prendimiento, se debían reponer los pies y manos que faltasen y fabricar una alabarda, una partesana ${ }^{58}$ y varias espadas de madera. A estas alturas, la lectura de la escritura nos ha dejado ya con bastantes dudas respecto a la composición de los pasos, pues ni siquiera conocemos el número exacto de las imágenes en el de la Oración en el Huerto y en el del Prendimiento. En el del Huerto, necesariamente tenía que estar además de Cristo, San Pedro, San Juan y Santiago ${ }^{59}$, y el ángel, pues se menciona la necesidad de un armazón para él ${ }^{60}$. La escena del Prendimiento tenía que integrar por su parte a Cristo, Judas, algunos de los discípulos, cuando menos dos soldados y el siervo del pontífice o sumo sacerdote, que San Juan identifica como Malco, al cual San Pedro corta la oreja ${ }^{61}$. En el paso de la Flagelación se sintetizan dos escenas de la Pasión, al colocarse al gallo de la negación de San Pedro en lo alto de la columna a la que Jesús es atado. Precisaba este de la composición de las manos y dedos del Salvador y de la reposición de los pies y manos que faltaban. Respecto al del Ecce Homo, se despacha con un escueto «componer lo que le hiçiere menester». Para el paso de Cristo cargando con la cruz, había de «hacer tres armaçones con manos, pies que faltasen y haçer la cruz con las insignias que le tocasen. $\mathrm{Y}$ a de componer la cabeça de los sayones y todo lo más que tocare a su ofiçio de escultura y juntamente la cabeça de la Reina Elena, componer lo [que] hiçiese menester». La presencia de la figura de Santa Elena, madre del emperador Constantino, en referencia al episodio

\footnotetext{
${ }^{58}$ Según Sebastián de Covarrubias: «Arma enhastada y muy usada en los palacios de los reyes, para guarda suya, dicha por otro nombre alabarda. Díxose de los partos, por ser arma que ellos usaron». Tesoro de la Lengua Castellana o Española. Madrid-México. Turner, 1984. Ed. facs. 1611, p. 855. Según María Moliner: «Especie de alabarda con el hierro muy grande, cortante por ambos lados y con la parte inferior en forma de media luna. Fue insignia de los cabos de infantería». Diccionario de uso del español. Madrid. Gredos, 1982, vol. 2, pp. 648-649.

${ }^{59}$ Mc 14, 33. Mt. 26, 37.

${ }^{60}$ Se seguiría en esto a Lucas, 22,43 . «Se le apareció un ángel del cielo, que le confortaba».

${ }^{61}$ Mt. 26, 51-'54. Mc 14, 47. Lc. 22, 50. Jn. 18, 10.
}

"CUADERNOS DE ESTUDIOS GALLEGOS", Tomo XLIII, Fascículo 108, Santiago 1996. 
de la Invención de la Vera Cruz nos muestra un nuevo caso de agrupación de escenas sacras.

El resto de las condiciones se limitan a precisar que se ha de emplear madera de castaño y nogal, nuevo y seco y que los armazones han estar bien ensamblados y pesar lo menos posible. El pago total que recibiría el escultor era de 1.050 reales de vellón.

Son muchos los datos que se nos ocultan de estos conjuntos escultóri$\cos$, pero lo que puede obtenerse posee al menos la virtud de proporcionar en lo que a los pasos procesionales toca, una tipología y una fecha de referencia.

\section{DOCUMENTOS}

\section{I}

\section{3-marzo-26}

Poder para pleitos dado por José Vázquez de Córdoba, Jerónimo de Castro, Pedro Ramírez, Jacobo de Eneros, Miguel de Romay y Juan Antonio Rodríguez, escultores, en razón del pago de las alcabalas.

A.H.U.S. Prot. 3106, fol. 6, esc. López de Seoane y Espantoso, Antonio.

«Poder para pleitos de Joseph Vazquez de Cordoba y otros escultores.

En la ciudad de Santiago, a veinte y seis dias del mes de março de mill seiscientos y nobenta y tres años, ante mi scrivano y testigos, parescieron presentes Joseph Vazquez de Cordoba, Geronimo de Castro, Pedro Ramirez de Arellano, Jacobo de Eneros, Miguel de Romay y Juan Antonio Rodriguez de Castineyra, todos del arte de la escultura y veçinos deste ciudad e dijeron que estan y son conçedidas muchas preminencias, esenciones y prorrogativas por los señores reyes de España, mandadas guardar y oservar a los que en ellos ussasen en tal profession de tales escultores y que a ellos y a los mas que la ussan en esta dicha ciudad no se las quieren guardar ni oservar, antes les oprimen y obligan a todo genero de contribuycion y ofiçios concejiles y otras mas cossas a que no deven ser obligados por dichas preeminencias y que agora nobamente a venido a sus notiçias que los da dicha arte y profesion como de pintores que residen en la villa de Madrid, corte de Su Magestad y señores de su Real

"CUADERNOS DE ESTUdIOS GALLEGOS", Tomo XLIII, Fascículo 108, Santiago 1996. 
y Supremo Consejo de Castilla, sobre la oservançia de dichas preminencias y ganado sentencia y carta executoria a su favor y agora por la mejoria y remedio que en dicho lugar aya y conbenirles a su derecho, dijeron todos juntos y cada uno de por si que dan y otorgan todo su poder cumplido, el que es necesario y de derecho se requiera y sea neçesario y mas deva y pueda baler con aprobacion y rateficacion de todo lo echo y obrado y con clausula de que lo pueda jurar y sustituir las veçes necessarias, al liçenciado Don Gregorio de Leyra y Tavoada, residente en dicha villa de Madrid, para que en nombre de los otorgantes y representando sus propias personas pueda pareçer y paresca ante Su Magestad y señores de su Real y Supremo Consejo de Castilla y ante otros jueces y Justiçias a donde conbenga y sea neçesario y pueda presentar el y sus sustitutos quales quiera memoriales peticiones pedimentos y otros papeles y recaudos que conbenga y sean necesarios, expeçialmente en orden a que a favor de los otorgantes se mande librar testimonio y executoria de dicho pleyto referido con ynsercion de dicha sentencia, exceuciones, preminencias y prorrogativas y pidan que con ellos y a su favor se entiendan y se les guarden y ansi qualesquiera reales decretos y provisiones y mas autos $[\ldots] \gg$

Firmado por Joseph Vazquez de Cordoba, Jeronimo de Castro y Losada, Jacobo de Heneros, Pedro Ramirez de Arellano, Miguel de Romay y Jose Antonio Rodriguez de Castineyras.

1694-julio-24

Contrato entre Miguel de Romay, escultor y el mayordomo de la cofradía de la Vera Cruz para recomponer los pasos procesionales de la dicha cofradía.

A.H.U.S. Prot. 3278, fol. 34, esc. Quintero de Villar, Gonzalo.

«Concierto de obra entre Bartolome Couxill y Miguel de Romay, escultor y obligacon que este hace de hacerla.

En la ciudad de Santiago, a veinte y seis dias del mes de jullio de mill y seiscientos noventa y quatro años, ante mi scrivano y testigos pareçieron presentes de una parte Bartolome Couxill, vecino desta ciudad y de la 
otra Miguel de Romay, escultor, tambien vecino della. Y el dicho Bartolome de Couxill dixo que el mayordomo y cofrade de la cofradia de la Santa Vera Cruz, colocada en el convento de San Francisco de esta ciudad por su cabildo que tuvieron a los tres de mayo pasado deste año segun passo por ante Juan Alba, scrivano, libertaron a Rodrigo Albor, Juan Vazquez de Ulloa, Francisco Perez Viqueira y Antonio Rodriguez de Castro, vecinos desta ciudad de los oficios de vicario y mayordomos de dicha cofradia con la calidad de que cada uno habia de pagar y entregar seiscientos reales de vellon para la composicion y manifectura de los pasos de que se compone dicha procesion en el dia de Jueves Santo de cada año y los mas de la cofradia. Y que para este ministerio habia de entrar este caudal en poder de Don Bartolome Menendez, vezino desta ciudad, quien habia de entregarlo con recibos y para axustarlo con maestro que lo hiciesse dieron facultad a dicho Bartolome de Couxill y a Don Diego de Romay, maestro de obras, que por haberse falleçido, fue preciso cargar dicho Couxil con el ajuste. Y habiendolo hecho al menos coste que pudo, contrato con dicho Miguel de Romay el que corriese con ello y lo capitularon el que lo habia de hacer en esta forma. En el passo de la cena, hacer las armaçones de las treçe figuras y componer las cabeças y manos y, la cabeça del Salvador y San Juan, todo de nuevo. El paço del guerto: armaçones de todas las figuras, pies y manos y la cabeça de San Juan y la armaçon del anxel. El paço del prendimiento, las armaçones de todas las figuras, pies y manos que le faltaren, con las insignias, como son una alabarda y una partesana y sus espadas de madera. El paço de la coluna, las armaçones de las dos figuras con sus pies y manos y las insignias de los azotes y un gallo encima de la coluna, componiendo las manos y dedos del Salvador. El passo del Esse Omo, componer lo que le hiçiere menester. El passo de la cruz a cuestas, hacer tres armaçones con manos, pues que faltasen y haçer la cruz on las insignias que le tocasen. Y a de componer la cabeça de los sayones y todo lo mas que tocare a su ofiçio de escultura y juntamente al cabeça de la Reina Elena, componer lo [que] hiçiese menester. $Y$ todo de madera de castaño y nogal nuevo y seco. $Y$ las armaçones de ensamblacion y de buena perfecion, el menor pesso, a vista y contento de dicho Bartolome Couxill y de qualquier maestro de obras y del arte de toda satisfacion, sin que aiga tacha que ponerle a toda la obra. La qual en esta conformidad se obliga con su persona y bienes, muebles y raices, habidos y por haber, dicho Miguel de Romay de darla

"CUADERNOS DE ESTUdIOS GALLEGOS", Tomo XLIII, Fascículo 108, Santiago 1996. 
hecha y perfeçionada, conforme va dicho y a todo contento en todo el mes de octubre primero que viene de este año, ha que ha de ser compelido y apremiado y por precio y quantia de mill y cinquenta reales de vellon en que se ajusto dicho Bartolome Couxill. Los quatrocientos dellos que ahora en contado reçivio de mano de dicho Don Bartolome Menendez en moneda de vellon que los importaron, de cuya paga, entrega y recivo, yo scrivano doy fee. Y los trescientos reales se los ha de pagar el susodicho en los dos meses de agosto y septiembre. Y los trescientos cinquenta restantes a fin de dicho mes de octubre fenecida la obra. [...]»

Figuran como testigos don Andrés Diaz Saavedra, vecino de San Pedro de Cumeiro, Mauro Antonio Campo, ensamblador y Antonio do Cabo.

Firmado por Bartolome de Couxil y Miguel de Romay.

\section{III}

Relación de entalladores, ensambladores y escultores por orden de aparición, citados en las listas de votantes en la elección de procurador general de la ciudad de Santiago para el año 1687.

A.H.U.S. Sección Ayuntamiento. Libro de consistorios de 1686, fol. 349 yss.

Jerónimo García, ensamblador, Antonio de Barrios, entallador, Antonio de Pias, ensamblador, Jacinto de Barrios, entallador, Andrés García, ensamblador, Juan de Illobre, entallador, Jerónimo Patiño, entallador, Francisco Martínez, entallador, Jacobo de Eneros [escultor], Juan Rocha, entallador, Jacinto Suares, ensamblador, Domingo Fernández, ensamblador, Pedro Fernández, ensamblador, Juan de Bustelo, entallador, Jerónimo de Castro [escultor], Juan Cabrera, ensamblador.

"CUADERNOS DE ESTUDIOS GALLEGOS", Tomo XLIII, Fascículo 108, Santiago 1996. 